\title{
Effect of surfactant concentration and solvent used for washing in the preparation of $\mathbf{Y b}: \mathbf{Y}_{2} \mathbf{O}_{3}$ transparent ceramics
}

\author{
Pratik Deshmukh*, S. Satapathy**, M. K. Singh, P. K. Gupta \\ Nano Functional Materials Laboratory, Laser Materials Development \& Devices Division, \\ Raja Ramanna Centre for Advanced Technology, Indore 452013, India \\ *ppdeshmukh@rrcat.gov.in, ${ }^{* *}$ srinu73@rrcat.gov.in
}

PACS 81.20.Ev; 78.67.Bf; 42.70.Hj

DOI 10.17586/2220-8054-2016-7-3-534-537

\begin{abstract}
Nanoparticles of $\mathrm{Yb}: \mathrm{Y}_{2} \mathrm{O}_{3}$ have been synthesized by co-precipitation synthesis routes. The $\left(\mathrm{NH}_{4}\right)_{2} \mathrm{SO}_{4}$ surfactant was added to $\mathrm{Y}(\mathrm{OH})_{3}$ precipitate during synthesis to control the size, morphology, agglomeration and phase of nanoparticles. The dried precipitates were calcined at $900{ }^{\circ} \mathrm{C}$ to obtain the desired cubic phase $\mathrm{Yb}: \mathrm{Y}_{2} \mathrm{O}_{3}$ nano particles. In the present study we reported the effects of surfactant concentration on size, morphology, agglomeration and phase of $\mathrm{Yb}: \mathrm{Y}_{2} \mathrm{O}_{3}$ nanoparticles. However the addition of surfactant is not enough to get nonagglomerated nanoparticles. The extracted precipitate should be washed in proper solvent to avoid formation of hard agglomerate during drying. Hence the effects of washing solvent (i.e. water and methanol) on agglomeration and transparency were also reported. The transparency of the sintered pellets, prepared by varying the surfactant concentration and washing solvent, was evaluated. A transparency of $\sim 80 \%$ at $1500 \mathrm{~nm}$ was achieved in $1 \mathrm{~mm}$ thick $\mathrm{Yb}: \mathrm{Y}_{2} \mathrm{O}_{3}$ ceramic pellet by optimization of the surfactant and washing solvent.
\end{abstract}

Keywords: transparent ceramics, $\mathrm{Yb}: \mathrm{Y}_{2} \mathrm{O}_{3}$, surfactant.

Received: 4 February 2016

\section{Introduction}

Nanotechnology and sintering techniques can be utilized in combination for the fabrication of rare earth-doped yttria transparent ceramics because the high surface area of the nanoparticles facilitates sintering, permitting one to reach full density more rapidly at temperatures far below the melting point of the material [1,2]. The fabrication of $\mathrm{Yb}$ doped $\mathrm{Y}_{2} \mathrm{O}_{3}$ transparent ceramic involves the synthesis of non-agglomerated nanoparticles of $\mathrm{Yb}$ doped $\mathrm{Y}_{2} \mathrm{O}_{3}$ and sintering of pressed pellets (prepared using a nanopowder) at high temperatures under low pressure [3]. Of the different methods adopted for the preparation of non-agglomerated nanoparticles, the co-precipitation method has been widely used for nanopowder synthesis because the particle size and morphology can be efficiently controlled [4].

However, in case for the synthesis of $\mathrm{Yb}: \mathrm{Y}_{2} \mathrm{O}_{3}$ nanopowders using co-precipitation method, the $\mathrm{Y}(\mathrm{OH})_{3}$ precipitate underwent severe agglomeration during drying. This agglomeration led to poor sinterability for the $\mathrm{Yb}: \mathrm{Y}_{2} \mathrm{O}_{3}$ nanopowder obtained after calcination. Thus, special measures were adopted during precipitation, such as addition of surfactant to create non-agglomerated nanoparticles. It is reported that the surfactant $\left(\mathrm{NH}_{4}\right)_{2} \mathrm{SO}_{4}$, which adsorbs on the surface of the $\mathrm{Y}(\mathrm{OH})_{3}$, hinders the bonding between particles [5,6]. It has also been shown that the morphology of precursors was affected by the $\left[\left(\mathrm{NH}_{4}\right)_{2} \mathrm{SO}_{4}\right] /\left[\mathrm{Nd}: \mathrm{Y}_{2} \mathrm{O}_{3}\right]$ ratio (measured by weight) [7]. However, the effect of surfactant concentration on the crystallographic phase of the prepared nanopowder has not been investigated yet. Similarly, the solvent used to wash the precipitate plays a crucial role in the agglomeration of nanoparticles. Some solvents remove the surfactant from the particle surface and cause hard agglomeration during drying of precipitate [8]. The chemical nature of the washing solvent may be different for dissimilar oxide nano particles.

Thus, the aim of this work is to study the effect of surfactant concentration on the size, morphology, agglomeration and phase of $\mathrm{Yb}: \mathrm{Y}_{2} \mathrm{O}_{3}$ nanoparticles obtained using the co-precipitation method as well as its influence on the transparency of sintered pellets incorporating these nanoparticles. The effect of the solvent used for washing the precipitate on the transparency of the pellet is also evaluated.

\section{Experimental}

A $0.2 \mathrm{M}$ mother solution of $\mathrm{Yb}$ doped $(1 \mathrm{~mol} \%) \mathrm{Y}_{2} \mathrm{O}_{3}$ (using $\mathrm{Yb}_{2} \mathrm{O}_{3}$ and $\mathrm{Y}_{2} \mathrm{O}_{3}$ powders of purity $99.99 \%$; make: Alfa Aesar) was prepared by dissolution with dilute nitric acid. The mother solution was titrated with $1 \mathrm{M}$ aq. ammonia by normal striking. A white jelly like basic $\mathrm{Yb}: \mathrm{Y}(\mathrm{OH})_{3}$ precipitate was formed during the titration which was controlled by measuring online $\mathrm{pH}$. After aging, the hydroxide precipitate was divided into five equal parts. In order to investigate the effects of surfactant concentration on the transparency of sintered $\mathrm{Yb}: \mathrm{Y}_{2} \mathrm{O}_{3}$ pellets, $\left(\mathrm{NH}_{4}\right)_{2} \mathrm{SO}_{4}$ surfactant having 5, 10, 15, 20 and $30 \mathrm{wt} \%$ concentration was added to each part of the precipitate separately i.e. $5 \mathrm{wt} \%$ of $\left(\mathrm{NH}_{4}\right)_{2} \mathrm{SO}_{4}$ solution were added into first part of hydroxide precipitate and so 
on. Then, the samples were washed using methanol and dried in an oven. Calcination was performed at $900{ }^{\circ} \mathrm{C}$ for $4 \mathrm{~h}$ in air. Then, the calcined powders were pressed under a pressure of $150 \mathrm{MPa}$ using a uniaxial press. To show only the effect of morphology and particle size distribution on pellet's transparency, a cold isostatic press (CIP) was not used for pellet pressing. The pellets were sintered at $1750{ }^{\circ} \mathrm{C}$ for $5 \mathrm{~h}$ using a high temperature high vacuum furnace with a tungsten mesh heating element (Hind High Vacuum High Temperature Furnace, Hind High Vac. Co (P). Ltd., Bangalore). Finally, the pellets were polished using $300 \mathrm{~nm}$ alumina powders. Phase identifications of the $\mathrm{Yb}(1 \mathrm{~mol} \%): \mathrm{Y}_{2} \mathrm{O}_{3}$ nanopowders prepared using different surfactant concentrations were performed using $\mathrm{X}$-ray diffractometry (XRD) (Cu-K $\alpha$, Rigaku) and morphology was observed by field emission scanning electron microscope (FESEM, Zeiss).

\section{Results and discussion}

X-ray diffraction (XRD) patterns of $\mathrm{Yb}(1 \mathrm{~mol} \%): \mathrm{Y}_{2} \mathrm{O}_{3}$ powders prepared using different surfactant concentrations are shown Fig. 1. The XRD patterns of these powders are in good agreement with that of $\mathrm{Y}_{2} \mathrm{O}_{3}$ (Standard JCPDS, Card no. 41-1105) crystal $[9,10]$. The results revealed that the precursor transformed to cubic phase of $\mathrm{Y}_{2} \mathrm{O}_{3}$ crystals after calcination at $900{ }^{\circ} \mathrm{C}$ for $5 \mathrm{wt} \%$ and $10 \mathrm{wt} \%$ of surfactant concentration but for $15 \mathrm{wt} \%$ and above surfactant concentrations, it transforms to a mixed phase i.e. combination of cubic and monoclinic phase $\mathrm{Y}_{2} \mathrm{O}_{3}$ crystal. The reflection from the monoclinic phase (space group $\left.\mathrm{C} 2 / \mathrm{m}\right)\left(\mathrm{Y}_{2} \mathrm{O}_{3}\right.$ : PDF 44-0399) appeared in the diffraction patterns for 15, 20 and $30 \mathrm{wt} \%$ surfactant concentration as shown in Fig. 1 [10].

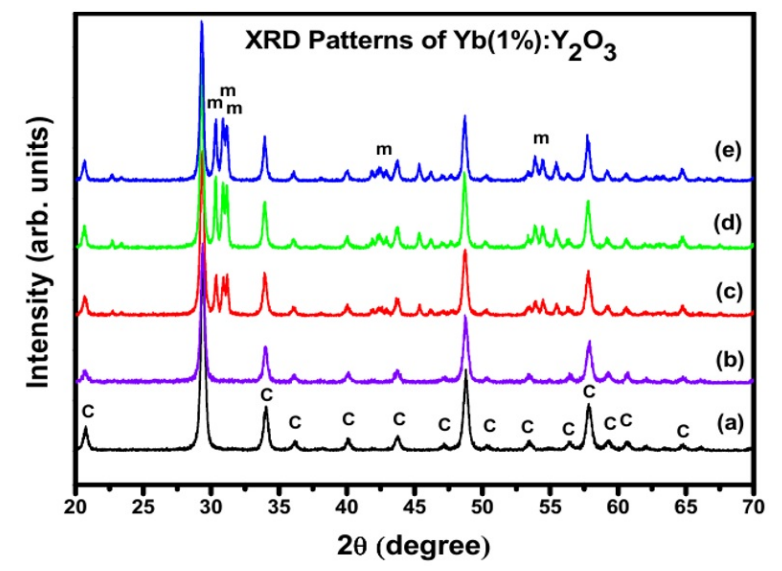

FIG. 1. X-ray diffraction patterns of $\mathrm{Yb}(1 \mathrm{~mol} \%): \mathrm{Y}_{2} \mathrm{O}_{3}$ nanopowders prepared using different surfactant concentrations: (a) $5 \mathrm{wt} \%$, (b) $10 \mathrm{wt} \%$, (c) $15 \mathrm{wt} \%$, (d) $20 \mathrm{wt} \%$ and (e) $30 \mathrm{wt} \%$

Scanning electron micrographs of $\mathrm{Yb}(1 \mathrm{~mol} \%): \mathrm{Y}_{2} \mathrm{O}_{3}$ powder prepared using different surfactant concentrations are shown in Fig. 2. The morphologies of the $\mathrm{Yb}(1 \mathrm{~mol} \%): \mathrm{Y}_{2} \mathrm{O}_{3}$ nanoparticles are nearly spherical and are unchanged with variation in surfactant concentration. The existence of $\mathrm{SO}_{4}^{2-}$ on the surface of yttrium hydroxide precursors at comparatively high temperature inhibits volume diffusion and/or grain boundary diffusion, and then particle growth proceeds by surface diffusion or evaporation-condensation, which results in collapse of agglomerates into well-dispersed nanopowders [12].

Photographs of sintered pellets of $\mathrm{Yb}(1 \mathrm{~mol} \%): \mathrm{Y}_{2} \mathrm{O}_{3}$ prepared using different surfactant concentrations i.e. (a) $5 \mathrm{wt} \%$, (b) $10 \mathrm{wt} \%$, (c) $15 \mathrm{wt} \%$, (d) $20 \mathrm{wt} \%$ and (e) $30 \mathrm{wt} \%$ are shown in Fig. 3. As is clearly visible, the transparency of the sample (a) and (b) is so good, as to allow the easy reading of the underlying print, however, the transparency does seem to be decreased at higher surfactant concentrations. This may be due the transformation of the phase from cubic to a mixed one (as evident from Fig. 1).

Figure 4 shows the photograph of sintered pellet of $\mathrm{Yb}(1 \mathrm{~mol} \%): \mathrm{Y}_{2} \mathrm{O}_{3}$ prepared by using $5 \mathrm{wt} \%$ concentration of surfactant and water as the washing solvent. The simple change in washing solvent from methanol to water during synthesis would appear to lead to a drastic decrease in the transparency of the sintered $\mathrm{Yb}(1 \mathrm{~mol} \%): \mathrm{Y}_{2} \mathrm{O}_{3}$ pellet. This is due to the formation of high strength agglomerates after washing with the liquid having higher surface tension like water (greater than methanol) [13].

Using the above experimental conditions, we have successfully fabricated highly transparent $\mathrm{Yb}(1 \mathrm{~mol} \%)$ : $\mathrm{Y}_{2} \mathrm{O}_{3}$ ceramics pellets (transparency $\sim 80 \%$ in visible-IR region without considering Fresnel's reflection). 

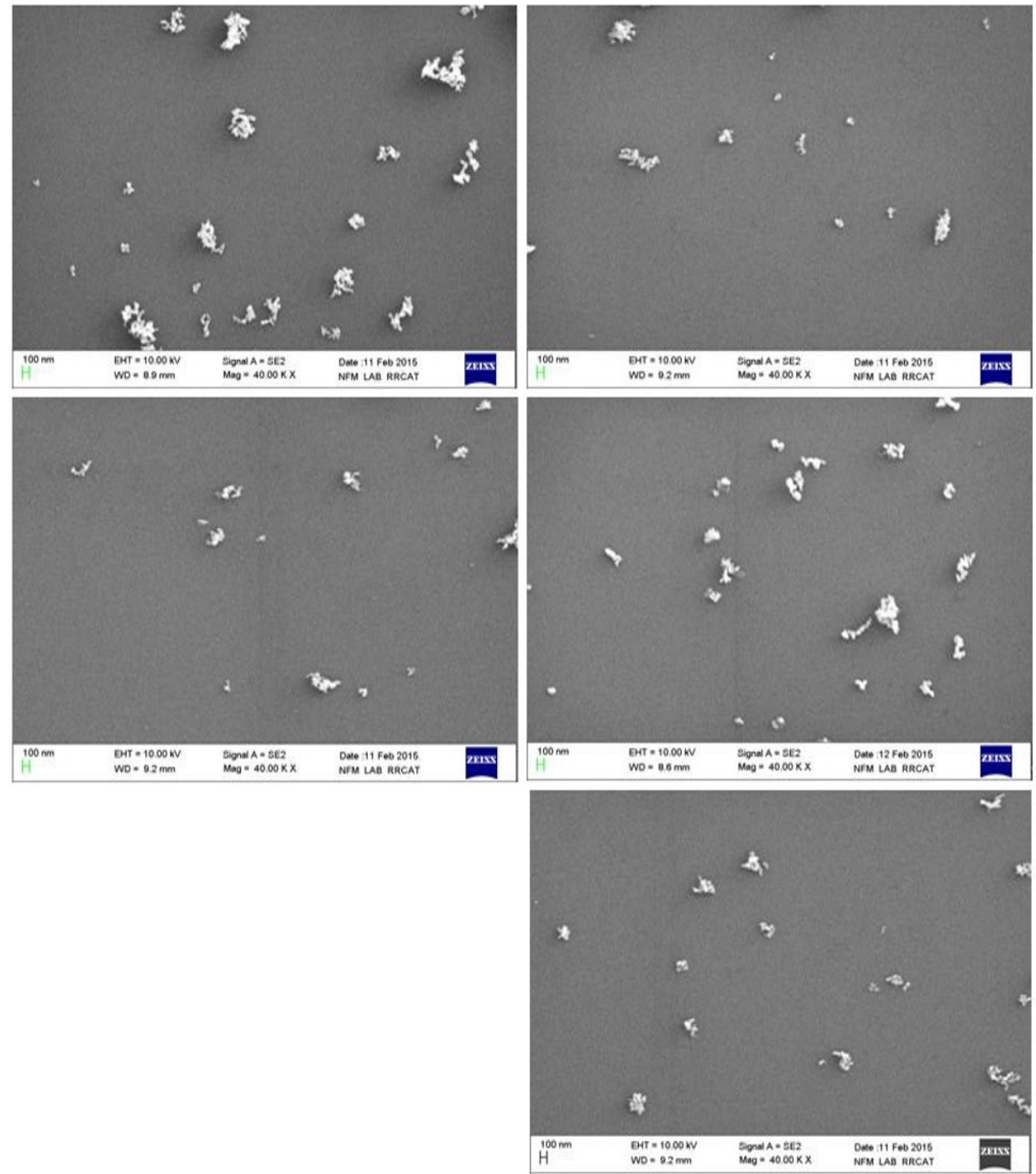

FIG. 2. FESEM images of $\mathrm{Yb}(1 \mathrm{~mol} \%): \mathrm{Y}_{2} \mathrm{O}_{3}$ nano powders prepared using different surfactant concentrations: (a) $5 \mathrm{wt} \%$, (b) $10 \mathrm{wt} \%$, (c) $15 \mathrm{wt} \%$, (d) $20 \mathrm{wt} \%$ and (e) $30 \mathrm{wt} \%$

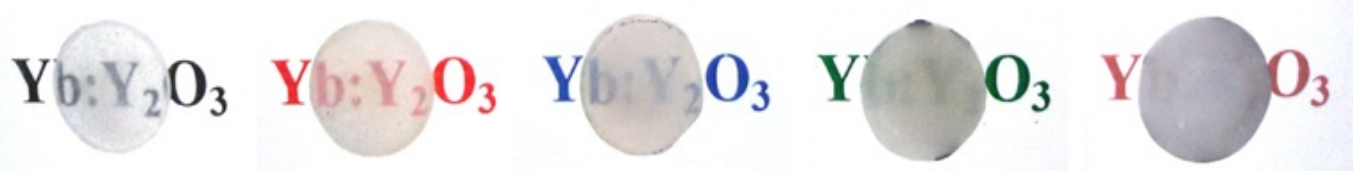

FIG. 3. Photograph of sintered pellets of $\mathrm{Yb}(1 \mathrm{~mol} \%): \mathrm{Y}_{2} \mathrm{O}_{3}$ prepared using different surfactant concentrations: (a) $5 \mathrm{wt} \%$, (b) $10 \mathrm{wt} \%$, (c) $15 \mathrm{wt} \%$, (d) $20 \mathrm{wt} \%$ and (e) $30 \mathrm{wt} \%$

\section{$\mathrm{Yb}: \mathrm{Y}_{2} \mathrm{O}_{3}$}

FIG. 4. Photograph of sintered pellet of $\mathrm{Yb}(1 \mathrm{~mol} \%)$ : $\mathrm{Y}_{2} \mathrm{O}_{3}$ prepared using $5 \mathrm{wt} \%$ of surfactant concentration and water as the washing solvent 


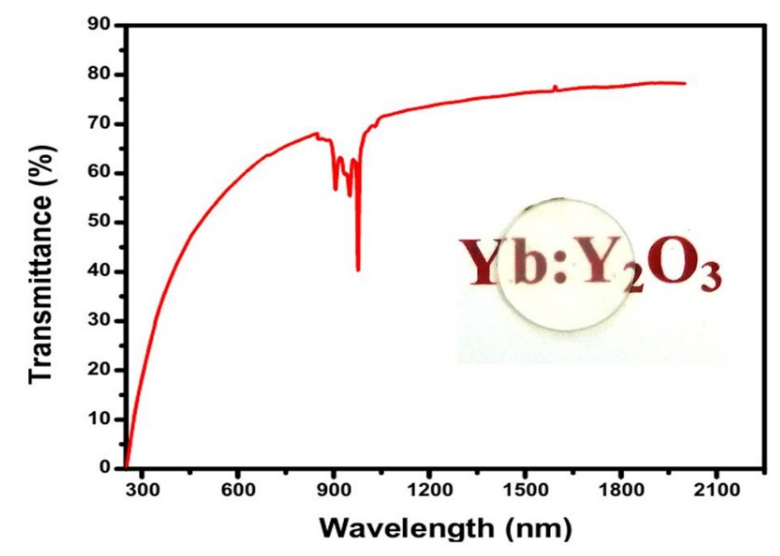

FIG. 5. Optical transmittance spectrum of a sintered pellet of $\mathrm{Yb}(1 \mathrm{~mol} \%): \mathrm{Y}_{2} \mathrm{O}_{3}$ and inset shows the photograph of transparent ceramic

\section{Conclusion}

The use of surfactant $\left(\mathrm{NH}_{4}\right)_{2} \mathrm{SO}_{4}$ during the synthesis of nanoparticles is helpful to control particle size and agglomeration. The excess concentration of it does not affect the particle morphology. Hence, the sinterability (which mainly depends on the size, agglomeration and morphology of the particles) of the all samples (prepared using different $\left(\mathrm{NH}_{4}\right)_{2} \mathrm{SO}_{4}$ concentrations) would remained same. Thus, the observed difference in transparency of $\mathrm{Yb}(1 \mathrm{~mol} \%): \mathrm{Y}_{2} \mathrm{O}_{3}$ sintered pellets is due to transformation of the phase from cubic to mixed (i.e. combination of cubic and monoclinic phase). Additionally, the surface tension of washing solvent affects the agglomeration during drying of the precipitate. The optimized synthesis parameters for $\mathrm{Yb}: \mathrm{Y}_{2} \mathrm{O}_{3}$ nanoparticles i.e. $5 \mathrm{wt} \%$ surfactant concentration and methanol as washing solvent have been used to successfully fabricate highly transparent $\mathrm{Yb}(1 \mathrm{~mol} \%): \mathrm{Y}_{2} \mathrm{O}_{3}$ ceramics pellets.

\section{References}

[1] Lu J., Lu J., et al. $\mathrm{Nd}^{3+}: \mathrm{Y}_{2} \mathrm{O}_{3}$ ceramic laser. Japanese Journal of Applied Physics, 40(2001), P. L1277-L1279.

[2] Shirakawa A., AkaichiK., et al. First mode-locked ceramic laser: femtosecond $\mathrm{Yb}^{3+}: \mathrm{Y}_{2} \mathrm{O}_{3}$ ceramic laser. Laser Physics, 2004, 14(11), P. $1375-1381$.

[3] Ikegami T., Mori T., et al. Fabrication of Transparent Yttria Ceramics through the Synthesis of Yttrium Hydroxide at Low Temperature and Doping by Sulfate Ions. J. Ceram. Soc. Jpn., Int. Ed., 1999, 107(3), P. 297.

[4] Ji-Guang Li, Takayasu Ikegami, et al. Co-precipitation synthesis and sintering of yttrium aluminum garnet (YAG) powders: the effect of precipitant. Journal of the European Ceramic Society, 2000, 20, P. 2395-2405.

[5] Saito N., Matsuda S-I., Ikegami T. Fabrication of transparent yttria ceramics at low temperature using carbonate-derived powder. J. Am. Ceram. Soc., 1998, 81(8), P. 2023-2028.

[6] Lu J., Ueda K.I.,et al. Neodymium doped yttrium aluminum garnet $\left(\mathrm{Y}_{3} \mathrm{Al}_{5} \mathrm{O}_{12}\right)$ nanocrystalline ceramics-a new generation of solid state laser and optical materials J. Alloys Comp, 2002, 341, P. 220-225.

[7] Wang H.Z., Gao L., Niihara K. Synthesis of nanoscaled yttrium aluminum garnet powder by the co-precipitation method. Mater. Sci. Eng., 2000, A288, P. 1.

[8] Gao L., Qiao H.C., Qiu H.B., Yan D.S. Preparation of Ultrafine Zirconia Powder by Emulsion Method. J. Eur. Ceram. Soc., 1996, 16, P. 437.

[9] Wen L., Sun X., et al. Synthesis of yttria nanopowders for transparent yttria ceramics. Opt. Mater., 2006, 29, P. 239.

[10] Gajovic A., Tomasic N., et al. Influence of mechanochemical processing to luminescence properties in $\mathrm{Y}_{2} \mathrm{O}_{3}$ powder. $J$. Alloys and Compd., 2008, 456, P. 313-319.

[11] JCPDS International Centre for Diffraction DATA, Swarthmore, PA, 1996.

[12] Takayasu I., Li J.G., Sakaguchi I., Hirota K. Morphology change of undoped and sulfate-ion-doped yttria powders during firing. J. Am. Ceram. Soc., 2004, 87(3), P. 517-519.

[13] Mouzon J., Oden M., Tillement O., Jorand Y. Effect of drying and dewatering on yttria precursors with transient morphology. J. Am. Ceram. Soc., 2006, 89(10), P. 3094-3100. 